\title{
Apuntes para un esbozo del valor de la tragedia para el akratếs
}

\author{
Massiel Román Molero \\ Pontificia Universidad Católica del Perú
}

Resumen: En el pasaje 1147b6-9 de la Ética Nicomáquea, Aristóteles subraya que el akratếs es capaz de arrepentimiento sin indicar cómo, pues ello debe ser escuchado de los fisiólogos. Este trabajo, no obstante, sostiene que Aristóteles no deja este problema sin respuesta: dado que la educación es el marco en el que el hombre se ejercita, a lo largo de su vida, en el buen vivir, la construcción de la acción trágica en la Poética puede verse como una herramienta pedagógica que permite una profundización en el conflicto entre la razón y las pasiones del akratếs, y cuyo genuino aporte estriba en su capacidad de explotar sus páthē para él y encauzarlas hacia una reflexión, a través de un ejercicio deductivo, sobre su propia condición.

Palabras clave: Aristóteles, Ética, Poética, akrasía, tragedia

Abstract: "Notes for an outline of the value of tragedy for the akratếs". In The Nicomachean Ethics, Aristotle points that the akratếs is able of regretting, but provides no explanation, since that should be said by physiologists (1147b6-9). However, this work argues that Aristotle does not leave this problem without an answer; given that education is the framework in which mankind exercises in his entire life, in good living, the construction of the tragic action in the Poetics can be seen as a pedagogic tool. This allows a deepening of the conflict between the akratés' reasoning and passions, whose genuine contribution lies in its ability to exploit his páthē for himself and channel them towards a reflection, through a deductive exercise, about his own condition.

Keywords: Aristotle, Ethics, Poetics, akrasía, tragedy 
Al analizar y discutir la naturaleza del akratếs en la Ética Nicomáquea VII, Aristóteles subraya que este, a diferencia del intemperante o autoindulgente (akólastos), es capaz de arrepentimiento (1985a, 1150b29-31). No se pronuncia sobre cómo esto ha de llevarse a cabo, pues "(e)l argumento, según el cual el incontinente se libera de su ignorancia y recobra su conocimiento (epistếmē), es el mismo que el del embriagado y el que duerme, y no es peculiar de esta pasión; pero esto debemos escucharlo de los fisiólogos" (1985a, 1147b6-9). Si esta última sentencia es vista solo como un paso de un estado exclusivamente físico a otro, en el cual el incontinente vuelve a su experiencia del mundo tal como cuando está sobrio, desde luego, este es un asunto del cual los fisiólogos deben encargarse. No obstante, aquella puede tener otra interpretación si se piensa el paso de este estado de ignorancia al conocimiento como un asunto de relevancia ética y política - pues las ciencias prácticas lidian con el buen vivir en la polis, y una vida dominada por las pasiones hasta los extremos degrada al hombre y a su capacidad de ejercer su felicidad y función propia, ya sea como hombre o ciudadano-, con lo cual resultaría siendo una preocupación también para el filósofo político. ¿Cuál es la fuente de su ignorancia? ¿Por qué, si sabe, falla?

La situación del akratếs, tal como será visto con mayor detalle en la sección $\S 2$, es particular. El akratếs "sabe" que no debe actuar mal, pero lo hace. En términos generales, dos de las causas principales son (i) impedimentos de tipo externo y (ii) un conflicto entre la razón y los apetitos y deseos, en los que estos últimos prevalecen. El primer tipo de obstáculo no es aquí de interés, pues escapa a su control; no obstante, el segundo es de importancia crucial porque le concierne en tanto hombre y ciudadano. Si lo que se busca es un arrepentimiento que conduzca al ejercicio de una mejor héxis y forma de vida, la respuesta no puede ser esencialmente fisiológica. La herramienta que sirva a este hombre tiene que estar relacionada con los apetitos, los deseos y la razón, en favor de esta última y, con todo, sin negar a los otros. Estos elementos -junto a otros que posteriormente serán 
expuestos- pueden hallar un encauce favorable en las funciones educativas ${ }^{1}$, catárquicas y reflexivas que puede cumplir la tragedia tal como es expuesta en la Poética.

Este trabajo tiene como intención realizar una aproximación inicial a esta relación. La argumentación siguiente está dividida en dos secciones. En la primera realizaré una breve aproximación a la compleja figura del akratếs; para ello, consideraré para la discusión principalmente lo expresado en la Ética Nicomáquea VII 3, 4 y 8, es decir, la akrasía, sus tipos y su relación con el conocimiento, dos pasiones específicas y el placer. Con esto en consideración, en la última sección se examinarán algunos elementos que podrían permitir pensar a la tragedia como una herramienta para el akratếs. En ese sentido, se realizará un acercamiento a la concepción de la educación para Aristóteles, la importancia de la formación de hábitos, en términos generales, en los hombres $-\mathrm{y}$, en especial, como se verá luego, para el akratếs- dada su influencia en sus aptitudes naturales y su capacidad de disponerlos hacia el discurso razonado. Ya que la educación en hábitos está relacionada con la formación del carácter moral, esta se dirige hacia la parte pasional y deseosa del alma, por lo que se revisará un argumento sobre esta relación. A partir de este punto, el trabajo se centrará en la tragedia y su estructura, el estudio de dos pasiones importantes para este trabajo -el miedo y la compasión-, y se plantearán otros argumentos con relación al carácter general de la poesía, la anagnórisis como elemento de la tragedia especialmente útil para el akratếs, la hamartía, la dimensión bella de la tragedia, su funcionalidad e importancia cognitiva. Finalmente, este último punto me llevará a considerar con mayor detalle el proceso cognitivo particular involucrado en la tragedia favorable para el akratếs.

1 Como insistiré en adelante, la intención de este texto no es reducir la tragedia a una función educativa ni comprometer su independencia alegando que puede someterse a la ética y la ciencia política. Como señala Aristóteles en la Poética, el poeta puede representar las cosas como él cree que son o que deben ser $(1999,1460 \mathrm{~b} 10)$. 
Aristóteles inicia la Ética Nicomáquea VII apuntando que la incontinencia (akrasía) es una de las disposiciones morales que debe evitarse (1985a, 1145a15-17). Según Aristóteles, "(s)e podría preguntar cómo un hombre que tiene recto juicio puede ser incontinente. Algunos dicen que ello es imposible, si se tiene conocimiento: pues, como Sócrates pensaba, sería absurdo que, existiendo el conocimiento, otra cosa lo dominara y arrastrara como a un esclavo" (1985a, 1145b22-25). Sin embargo, esa postura no se verifica en la realidad. Usualmente, pese a que una persona entiende que no debe hacer una acción, la hace. Puede aducirse que se debe a la existencia de una disposición interna de algunos hombres hacia placeres en exceso; no obstante, una simplificación tal resultaría problemática, pues, en ese caso, el estado del akratếs sería el mismo que del akólastos, pese a que el primero, a diferencia de él, sabe que no debe actuar de tal forma. Además, el primero tiene un conocimiento general de lo que es bueno. Pero ¿cómo lo sabe?, ¿contradice realmente a su juicio al actuar mal? Para conocer más sobre el hombre acrático, entonces, revisaré (i) cómo se relaciona con el conocimiento y (ii) con las pasiones y el placer².

Según la distinción presentada en Ética Nicomáquea VII, entender o saber (epistasthai) algo puede darse en dos sentidos: tener (échein) este conocimiento sin usarlo (potencialmente), y tenerlo y usarlo (actualmente). Sobre la base de esta diferencia, dice Aristóteles, se construye otra entre hacer lo que no se debe poseyendo el conocimiento sin ejercitarlo (mè theōroûnta), y teniéndolo y ejercitándolo (theōroûnta). Esto último -agrega- es lo verdaderamente extraño (Aristóteles 1985a, 1146b31-35). Iré por partes.

Para empezar, es legítimo preguntarse lo siguiente: ¿a qué se refiere Aristóteles con entender/saber (epistasthai)? Una ocurrencia de este término

2 Para esta división, tengo en consideración la diferencia que se suele hacer entre el grupo de explicaciones lógicas y fisiológicas de la conducta del akratếs (Charles 2009; Lorenz 2014). Esto se explorará principalmente en el primer punto. No obstante, creo conveniente examinar con mayor detenimiento la relación del akratếs con las pasiones, el placer y lo kalós, pues a través de este punto no solo se tiene una visión más cercana de él, sino que este representa el hilo que conectará con la Poética. 
ya ha aflorado y sido discutida en Ética Nicomáquea VI. Al hablar de las virtudes dianoéticas, Aristóteles mencionó que la ciencia o entendimiento (epistếmē) es un modo de ser demostrativo (héxis apodeiktikế), un estado en el que se conocen las causas de determinado fenómeno y en el que se es capaz de dar demostraciones o explicaciones de ciertas verdades a través de una adecuada referencia -ya que "conoce"3 - a los principios (1985a, 1139b30-35). Es una héxis y no una enérgeia: necesita actualizarse constantemente. El conocimiento de quien sabe no es accidental: dar explicaciones o demostraciones implica tener en mente el conocimiento de la forma en que, a través de las premisas -verdaderas por necesidad-y a partir del principio, puede llegarse a la conclusión (Aristóteles 1985a, 1139b35-36). Este es un criterio de saber relativamente exigente, pues implica tener un lógos claro sobre lo que se sabe, el cual debe estar presente en el momento en que se argumenta e involucra la posibilidad de argumentar frente a otros, entre otras cosas. Aristóteles implica la existencia de una noción de entendimiento mucho más amplia, ya que diferencia entre un entendimiento concebido estrictamente -dicho sea, universal y científico- y un tipo de entendimiento de corte perceptual (aísthēsis) (1985a, 1147b13-17). En el primer caso, el de la epistếmē apodeiktikế, el conocimiento se produce a través de la inducción de los primeros principios -o "captación" de estos por el noûs- (Aristóteles 1985a, 1141a; 1988b, 100b14-15) y el uso de los silogismos teóricos o científicos (Aristóteles 1985a, 1139b26-31). En el segundo caso, está involucrado un tipo de razonamiento usualmente llamado "silogismo práctico" (Nussbaum 1978, 182-184; Oriol 2004, 54-57, 63). Como el primero, el segundo tipo de conocimiento implica conocer la razón o explicación de por qué tales proposiciones del silogismo son verdaderas ${ }^{4}$. Pero en el silogismo de tipo práctico -a diferencia del otro- lo que resulta por necesidad es una acción ${ }^{5}$.

3 No me es posible entrar en el debate, sobre la base del último capítulo de los Analíticos Segundos, respecto de si es conocimiento por intuición, empírico o una extraña simbiosis de ambos. De ahí que use las comillas y el término de manera amplia.

4 Contemplar o ejercitar el saber refiere, ciertamente, a la realización del fin inmanente a la acción en la actividad. Por lo mismo, el ejercicio de este saber que se posee (i.e., sobre lo que debe hacerse o no) no se refiere solo al prestar atención al argumento que se esgrima, sino, fundamentalmente, al aprehender conscientemente la verdad de sus premisas, causas y razones.

5 No es objeto de este trabajo profundizar más en este interesante tema. Para una mayor caracterización del silogismo práctico, el estudio de Oriol (2004) me ha sido de mucha ayuda. 
¿Hace uso, entonces, el akratếs del silogismo práctico? Al argüir que sí aunque falle, Aristóteles (1985a, 1146b35-1147a4) divide la acción del akratếs en, por lo menos, dos clases. El primer tipo de hombre acrático responde a este tipo de error debido a una no-aprehensión de una de las premisas; el segundo tipo mantiene una relación peculiar con las pasiones. Veré de forma muy breve el primero. Según este pasaje, pese a que un hombre puede tener las dos premisas del silogismo (la menor y la mayor), puede obrar contra su conocimiento. Siguiendo a Rackham (Aristóteles 1934, 388389), a lo que apunta este discutido pasaje es a que, para la aplicación de un silogismo práctico, se requiere en realidad de dos silogismos ${ }^{6} \mathrm{y}$, en su defecto, hay dos tipos de entendimiento involucrados (Lorenz 2014, 247248). Según Oriol (2004, 72-73), uno es teórico y el otro práctico, y ambos se dan simultáneamente ${ }^{7}$. En la premisa menor del segundo silogismo la aplicación de la regla general es a la cosa en cuestión, pero parece que esto el incontinente (i) no lo sabe $-\mathrm{y}$, en ese caso, hablaríamos de una ignorancia de una premisa particular-, o (ii) según lo que hemos visto anteriormente con relación a hacer lo que no se debe poseyendo el conocimiento sin ejercitarlo y, por otra parte, teniéndolo y ejercitándolo, en cierto sentido, lo "sabe" y no lo "sabe". Por lo tanto, al aplicar el silogismo, no puede llegar a la acción, tal como se verá a continuación con mayor detalle. Entonces,

Sobre la diferenciación entre deliberación y silogismo práctico en la teoría de la acción de Aristóteles, sostiene: "La teoría de la acción a partir del deseo, con sus momentos deliberativo y decisional, atiende a un aspecto ineludible de la acción, el proceso psicológico que la antecede, pero no indica el aspecto racional y moral que toda acción (humana) incluye. Es este aspecto el que desarrolla la teoría del silogismo práctico" (Oriol 2004, 74).

6 En palabras de Rackham: "The next sentence points out that this application really requires two syllogisms; in the first, the personal term of the major premise is predicated in the minor of the particular person concerned (...) in the second, the other universal term is predicated in the minor of a particular thing about which the person is deliberating" (Aristóteles 1934, 388). Usando el ejemplo de Aristóteles: (1) La comida seca es buena para todos los hombres [el universal], (2) Yo soy un hombre [el particular]; por lo tanto, (3) La comida seca es buena para mí. Esto lo entiende el hombre acrático. El problema se presenta en el segundo silogismo que lo lleva a la acción: (1) La comida seca es buena para mí, (2) Esta planta es alimento seco [premisa particular, la aplicación]; por lo tanto, (3) Esta planta es buena para mí.

7 Una ocurrencia adicional aparece en Aristóteles 1985a, 1147a24-31. En la traducción de Rackham: "Again, one may also study the cause of Unrestraint scientifically, thus: In a practical syllogism, the major premise is an opinion, while the minor premise deals with particular things, which are the province of perception. Now when the two premises are combined, just as in theoretic reasoning the mind is compelled to affirm the resulting conclusion, so in the case of practical premises you are forced at once to do it" (Aristóteles 1934, 391). 
por ejemplo, puede suceder que alguien cometa un acto de adulterio -que conscientemente condena- sin saber que lo hizo con la pareja de un amigo.

Frente a esta akrasía, el segundo tipo se presenta como más problemático. Es posible, dice Aristóteles, tener "en cierto modo"y no tener el conocimiento, tal como es el caso del hombre que duerme, está loco o embriagado. Una condición tal en la que dominan las pasiones (páthē) es semejante a “(...) los accesos de ira (thymós), los apetitos de placeres amorosos y otras pasiones semejantes perturban, evidentemente, al cuerpo y, en algunos casos, producen la locura" (Aristóteles 1985a, 1147a14-17). Los incontinentes, pues, tienen estos modos de ser. En todo caso, como señalan Charles (2009, 50-51) y Lorenz (2014, 249-250), el tener y no tener entendimiento en este punto indica que Aristóteles tiene en consideración una condición que no implica solamente un equívoco o ignorancia sobre un particular, sino que compromete una condición específica del alma y/o fisiológica ${ }^{8}$.

Es interesante que Aristóteles, al continuar el tratamiento de esta akrasía, mencione que, en realidad, "El hecho de que tales hombres se expresen en términos de conocimiento nada indica (...), los principiantes de una ciencia ensartan frases, pero no saben lo que dicen, pues hay que asimilarlo y esto requiere tiempo" (1985a, 1147a18-24). Puede darse el caso de que estudiantes de una ciencia reciten de memoria argumentos, presenten sus proposiciones de forma clara y asimismo estén convencidos sobre su verdad. Pero mientras solo repitan lo dicho y no forme parte de su propio proceso de aprehensión de lo verdadero del contenido, en realidad, no lo han aprendido. El hombre acrático puede "saber" lo que está haciendo, pero, sin simultáneamente tener presente y utilizar su entendimiento para realizar conexiones inferenciales que expliquen los elementos del razonamiento involucrado, en cierto modo, realmente no sabe?

8 "What is characteristic of that special case [akrasía] is that the person in question is temporarily prevented from employing her understanding, given the psychological or physiological condition she is in" (Lorenz 2014, 250).

9 Al respecto, Charles $(2009,51)$ menciona que la falla aquí se trata de la falta de convicción racional (confidence) en la verdad de lo que el akratếs (o el estudiante, en este caso) dice; no obstante, para mí esta posición es equívoca. Anteriormente Aristóteles había dicho que, justamente, el problema no es la debilidad de la convicción porque hay hombres que están convencidos de lo que opinan tanto como otros respecto a lo que saben (1985a, 1146b25-30). 
El resultado de un silogismo práctico para el alma culmina en una acción que debe ejecutarse inmediatamente. ¿Qué impide que se haga así en el caso de este akratếs? Dos cosas: impedimentos de tipo externo y un conflicto entre la razón y el apetito o deseo, en el que estos últimos prevalecen. Por ejemplo, señala Aristóteles, cuando siguiendo a la razón un hombre debe evitar probar lo dulce $y$, al mismo tiempo, se presenta el deseo de probarlo dado que lo dulce es placentero, y esto en particular es dulce -y esta es la premisa que lo mueve a actuar-, el deseo resulta triunfante porque tiene la capacidad de "(...) mover todas y cada una de las partes del alma" (1985a, 1147a35-1147b5). ¿Cómo lo hace? El ser dominado por sus páthē no es dado necesariamente de forma violenta y abrupta. Puede ser de esa manera, mas es esencialmente un estado en el que uno, en vez de actuar, reacciona a algo externo a sí mismo, lo cual determina su acción (Rorty 1980, 275). El estado del hombre acrático es tal que, al ser dominado por sus pasiones, no es capaz de tener presente las conexiones explicativas entre sus silogismos -tal como el principiante en el estudio de la ciencia-, por lo que su entendimiento no se ejerce o actualiza de forma usual, a pesar de manejar las premisas. Ahora bien, dada su condición, ¿es voluntaria su acción? En efecto, pues el principio de la acción está en el hombre acrático en tanto agente, quien puede "conocer" las circunstancias concretas en las que radica su acción (Aristóteles 1985a, 1111a21-25). ¿Elige esa acción, entonces, por sí mismo? No, pues la elección (prohaíresis) es producto de una deliberación, pero el hombre acrático está en una condición cognitiva tal que se ve incapacitado para utilizar sus facultades racionales plenamente. No puede reflexionar en el momento $y$, por ello, tampoco puede aprehender las causas subyacentes a su razonamiento. Este hombre, por tanto, no es malo (kakós) porque no puede llegar a un nivel de reflexividad tal que su acción voluntaria se vuelva elegida. En ese sentido, en efecto, no elige hacer algo malo aunque lo haga, y es por ello mismo que es capaz de arrepentirse (Aristóteles 1985a, 1150b20-25ss).

Sin embargo, ¿qué sentido tiene un arrepentimiento que no conlleve a una mejor héxis? La acción acrática no sería tan problemática si no fuese tan fácil de ser repetida constantemente por un mismo hombre. En un caso tal, se puede pensar que inclusive el hombre incontinente puede degenerar en licencioso en tanto conciba que "(...) debe perseguir los placeres 
corporales porque tal es su constitución" (Aristóteles 1985a, 1151a11-14). Ante esa posibilidad, y dado que la forma en que las acciones del hombre son efectuadas es en función al placer y el dolor, es preciso detenerse a considerar rápidamente cómo Aristóteles esboza su concepción del placer. En el caso del hombre acrático existe una conexión entre las pasiones (páthē) y el placer/dolor que no puede ser pasada por alto. Revisaré este punto de forma muy breve ${ }^{10}$.

Según Retórica II,“(...) las pasiones (ta páthē) son, ciertamente, las causantes de que los hombres se hagan volubles y cambien en lo relativo a sus juicios, en cuanto que de ellas se siguen pesar (lýpe) y placer (hēdonế)" (Aristóteles 1990, 1378a20-22). Esta definición parece bastante amplia y lleva consigo preguntas tales como: ¿en qué medida son las pasiones "causantes" de cambios de juicio?, ¿qué significa que "se sigan" el pesar y el placer? A continuación, realizaré algunos apuntes al respecto que servirán como guía y ya en la última sección profundizaré en dos de las pasiones, el miedo y la compasión. Para empezar, en Retórica II, Aristóteles realiza algunas sugerencias importantes: al examinar una pasión se debe tener en cuenta (1) en qué estado se encuentra quien la experimenta, (2) contra quiénes (tísin) suele experimentarla y (3) por qué "asuntos" (epì poíois), i.e., cuál es la razón subyacente a ello (1990, 1378a22-24). Como Fortenbaugh plantea, la mención de objetos y una razón o fundamento (epì poíois) sugiere que Aristóteles no disocia la cognición de las emociones y que, más aún, las emociones no se conciben simplemente como sensaciones internas (2006, $22)^{11}$. Por otra parte, respecto de las pasiones como causantes de un cambio

10 En lo siguiente, me referiré al tratamiento de las pasiones siguiendo principalmente a Retórica II. Algunas cosas deben ser dichas al respecto. La elección, aunque problemática, es interesante. Diversos autores han calificado el tratamiento de la Retórica como superficial (frente a, por ejemplo, a Acerca del alma l); me parece que, siguiendo los estudios de Leighton (1982) y Fortenbaugh (2006), en realidad, es incompleto y, como Aristóteles señala, "apropiado para la ocasión". De ahí que en la bibliografía secundaria usualmente no se prescinda, para dar cuenta de dicho tema, de una lectura conjunta de textos como Acerca del alma (Aristóteles 1978) y las Éticas. Sin embargo, dada la extensión de este trabajo, solo es posible dar cuenta de algunos elementos importantes que sirvan a su objetivo principal que sí pueden hallarse en Retórica II. Por otra parte, respecto del problema de si lo expresado en Retórica II es una recopilación de opiniones o recoge también la propia de Aristóteles, véase la interesante discusión en Fortenbaugh (2006, 17-21).

11 Por ejemplo, en Retórica II la ira (thymós) se define como "(...) un apetito penoso de venganza por causa de un desprecio manifestado (phainoménēs) contra uno mismo o contra los 
de juicio, un pasaje de la Ética Nicomáquea VII resulta bastante ilustrativo: la ira (thymós) "(...) oye en parte a la razón, pero la escucha mal (...), a causa del acaloramiento y de su naturaleza precipitada, no escucha lo que se le ordena y se lanza a la venganza" (Aristóteles 1985a, 1149a25-31) ${ }^{12}$. Es a través de esta emoción que uno falla al percibir una situación y, con ello, tiene un juicio equívoco. Las pasiones pueden alterar la percepción ${ }^{13}$ y, por ende, el juicio. Más aún, con las pasiones el hombre ingresa en un estado tal en el que, como en el caso del hombre acrático, tiende hacia cierto tipo de juicios (i.e., voy a comer este dulce ahora) y excluye otros (i.e., los dulces no son saludables) de la situación. En último lugar, la conexión entre los placeres y dolores, y las pasiones parece ser de tipo conceptual, pues muchas de estas últimas son definidas en estos términos, y asimismo sus contrarios. Volveré sobre estos puntos en la última sección.

Sería razonable, según lo visto hasta el momento, concebir los placeres ${ }^{14}$ como un impedimento posible para las buenas acciones. Al parecer, Aristóteles ha dado razones para pensar esto desde el inicio de la Ética Nicomáquea. Por ejemplo, al señalar como candidatos a la eudaimonía a la vida teorética (teōrētikós), política y voluptuosa (apolaustikón), Aristóteles niega de plano a esta última esa posibilidad por ser, en tanto vida del placer, una vida "de bestias", preferida por el vulgo y los más groseros (1985a, 1095b14-19). Asimismo, indica que "(d)ebemos, por otra parte, tomar en consideración aquellas cosas hacia las que somos más inclinados (...). Esto lo conocemos por el placer y el dolor que sentimos, y entonces debemos tirar en sentido contrario, pues apartándonos lejos del error (hamartánein)

que nos son próximos, sin que hubiera razón para tal desprecio" (Aristóteles 1990, 1378a30). Aquí la traducción consultada pertenece a Racionero, quien al parecer sigue a Cope. No obstante, me parece que tener en mente que phainoménēs tiene una connotación que oscila entre lo real y lo aparente es necesario. Fortenbaugh (2006), siguiendo a Gomperz, lo toma de esta manera y argumenta a partir de allí a favor de la relación entre cognición y emoción presente en las páthē. Optar por esta traducción tiene la ventaja, me parece, de que el rango de casos que incluyen ciertas emociones se amplía: la ira, por ejemplo, como puede verse, se suscita aun si realmente no hay una ofensa contra el hombre (sobre la cual tiene una creencia verdadera: efectivamente, se ha dado), solo basta que crea que existe.

12 Volveré sobre este pasaje en la última sección.

13 Sobre la manera en que las pasiones alteran la percepción, véase Leighton (1982).

14 No me es posible detenerme en el debate sobre la naturaleza del placer. En lo que sigue, tan solo esbozaré algunos puntos que me parecen útiles para integrarlos en la discusión siguiente del §3 sobre las pasiones. 
llegaremos al término medio (méson) (...). En toda ocasión, hay que guardarse principalmente de lo agradable y del placer, porque no lo juzgamos con imparcialidad" (Aristóteles 1985a, 1109b1-9). La constitución de la héxis ética del hombre, entonces, inicia en cierta medida con el conocimiento de sí, cuyos referentes son los placeres y dolores ante los cuales tiene que tomar una determinada actitud de mesura. La experiencia del exceso y el defecto respecto a estas pasiones constituye el error que impide que el akratếs pueda hacer ejercicio de su conocimiento $\mathrm{y}$, por lo mismo, su perspectiva enfoca tan solo una parte del cuadro de su vida, que, como se verá más adelante, para él solo implica un resultado. Especialmente, por lo tanto, el hombre debe cuidarse del placer.

No obstante, Aristóteles también sostiene que "(...) el hecho de que todos, animales y hombres, persigan el placer es una señal de que el placer es, en cierto modo, el bien supremo" (1985a, 1153b25-27). Puede serlo si se recuerda que hay placeres que no involucran dolor ni apetito, tal como las actividades teoréticas "(...) en las que la naturaleza no necesita nada" (Aristóteles 1985a, 1152b35-1153a2). Los placeres pueden diferenciarse según sus fuentes, tipos de actividades o procesos de los cuales emerjan (Aristóteles 1985a, 1147b20-23; 1152b33-1153a2; 1153a8-11). Así pues, siguiendo a Rorty $(1980,276)$, hay (1) placeres que están asociados con las actividades necesarias del cuerpo, esto es, con la comida, la bebida y el sexo, asimismo los placeres de probar y tocar; y (2) placeres que no están asociados necesariamente con el ámbito físico, sino más bien (2.1) con actividades que son intrínsecamente deseables, como la actividad teorética y la aretế; (2.2) con procesos o actividades que son deseables incidentalmente, como los placeres que se experimenta al recuperarse de una enfermedad o los que son producto de una perversión; o (2.3) con actividades de una clase "intermedia", que no son intrínsecamente buenos ni malos, tales como la adquisición de bienes materiales, la riqueza, la victoria y el honor. Los primeros y los últimos placeres representan justamente un problema para el hombre acrático (Aristóteles 1985a, 1148a5-1148b1). 
Más allá del análisis de la Ética Nicomáquea VII sobre la causa del error en los hombres que los inclina hacia ese tipo de placeres ${ }^{15}$-especialmente, los corporales- (Aristóteles 1985a, 1154a15-21), quizá lo expuesto en un pasaje de la Ética Eudemia pueda ser de utilidad. “Además, en ambos casos [enkrasía y akrasía] se hallan presentes el placer y el dolor, pues el continente se aflige ahora al obrar contra su apetito, pero se alegra del placer que tiene en perspectiva, pues se aprovechará luego (...) y el incontinente se alegra al obtener con su incontinencia lo que desea, pero siente una pena anticipada, porque piensa que obra mal" (Aristóteles 1985b, 1224b15-20) ${ }^{16}$. Mientras que el enkratếs se "alegra" del placer que sentirá al no ceder ante sus apetitos y dirigirse más bien hacia el ejercicio de la templanza -lo que podría contar como la fuente de su continencia-, el akratếs, por el contrario, pareciera no sentir ese tipo de atracción hacia esa aretế. Sin embargo, la pena anticipada que siente puede ser asimismo una fuente importante de cambio si se halla una forma que responda a ella.

Para finalizar, es pertinente recordar que, para Aristóteles, aunque el akratếs puede caer en este estilo de vida como en un círculo vicioso, en él se salva lo mejor (áristos), que es el archế -o el fin en las acciones, según Aristóteles (1985a, 1151a15)-, ya que no persigue por convicción los excesos en los placeres corporales ni los contrarios al orthós lógos (1985a, 1151a10-26). Si en él se salva lo mejor, debe haber una manera por la cual su conducta de exceso frente al placer pueda ser regulada. Esta función la cumple la educación (paideía). En efecto, la formación de hábitos (héxis) es fundamental para el desarrollo de un carácter bueno en general y esto es proporcionado por la educación, de tal manera que a través de ella aprendemos a "(...) alegrarnos y dolernos como es debido" (Aristóteles 1985a, 1104b11-13). No obstante, el que el hombre deba ser formado de manera que pueda ejercer una conducta virtuosa en un futuro desde joven, tal como lo expresa Aristóteles en estas mismas líneas, ¿implica que no pueda haber vías alternas

15 Causas como el que los hombres huyen del dolor $y$, a causa de su exceso, buscan el placer excesivo; otros placeres son buenos incidentalmente; los hombres por naturaleza de cierta condición, i.e., irritables, siempre necesitan remedios, porque sus cuerpos son presa de deseos violentos y necesitan placeres intensos para calmar el dolor de sus cuerpos; etc.

16 Este punto es sugerido por Henry (2002). Me parece que, aunque no lo desarrolla en el sentido presente, es un aporte importante. 
que acompañen y ejerzan influencia en este proceso en la madurez, cuando estos pueden ya elegir? A mi parecer, no. La paideía no es exclusiva de una etapa, sino que es el marco en el que se desarrolla el ejercicio de toda una vida (Aristóteles 1985a, 1179b35-1180a517; 1988a, Pol. 1337a1-218). Es por ello que, a continuación, argumentaré por qué considero que la relación entre el akratếs y la acción trágica puede ser fructífera para el primero.

Para Aristóteles, tres son los factores que contribuyen al desarrollo de la virtud o el ser bueno del hombre ${ }^{19}$ : la naturaleza (phýsis), el hábito (êthos) y la razón (lógos) (1988a, 1332a39-40)20 . De los tres, me enfocaré en el segundo por su estrecha relación con la educación y su carácter intermedio: los hábitos influyen en las disposiciones naturales y disponen al hombre para el lógos o discurso razonado. Ahora bien, las virtudes que se aprenden por hábitos son justamente las que pertenecen a la parte deseosa (orektikòn/ epithymētikòn) o pasional (pathētikòn) y consisten, de manera muy general, en la aplicación del lógos a las pasiones mediante la phrónēsis (Aristóteles 1985a, 1102b-1103a). Si esto es así, entonces, la educación en hábitos que

17 En este punto, coincido con el análisis de Nussbaum: “En primer lugar, el crecimiento moral no se detiene bruscamente cuando el joven alcanza una determinada edad, ni siquiera un alto grado de desarrollo. Tanto cuando se refiere a la política como cuando reflexiona sobre la philia, Aristóteles entiende el crecimiento como un proceso permanente que necesita apoyo del exterior. Esto es cierto, sobre todo, en el caso de los adultos moralmente inmaduros, pero lo es también con respecto a los mejores" $(1990,436)$.

18 En la Política, hablando de que el trabajo y la guerra se realizan en vista del ocio y la paz, Aristóteles señala que "(...) a estos objetivos hay que orientar la educación de los que aún son niños y de las demás edades, que necesitan educación" (1988a, 1333b1-5). Aristóteles suele insistir en la importancia de la educación en la temprana edad, tal como en el pasaje citado de la Ética Nicomáquea (1985a, 1179b35-1180a5), pero, asimismo, pareciera que, si bien la importancia de la educación en la vida de los hombres no decrece con el tiempo, ya en la edad adulta esta va acompañada de la ley, las instituciones públicas y la vida como ciudadano. Así también, la educación inicia siendo una educación para el cuerpo y continúa siendo una para la "mente" (diánoia) (Aristóteles 1988a, 1338b4-8).

19 Ya que un estudio sobre la conexión entre la Ética y la Poética demandaría mucho más de lo que puede realmente ofrecer este trabajo, el argumento de esta sección se centra en solo tres puntos específicos.

20 Una variación de esta división se halla en Ética Nicomáquea X. Allí los tres factores son, respectivamente, la naturaleza, el hábito y la enseñanza (didachê) (Aristóteles 1985a, 1179b20-21). 
esté relacionada con la formación del carácter estará justamente encaminada hacia la parte pasional y deseosa del alma. Y, en efecto, esta aretế está dirigida a algo superior:"(...) primero es necesario que el cuidado del cuerpo preceda al del alma, y luego el cuidado del deseo; sin embargo, el cuidado del deseo es en función a la inteligencia (noûs), y el cuidado del cuerpo en función del alma" (Aristóteles 1988a, 1334b25-30). Hay, al parecer, tres tipos de educación: la referente al cuerpo, a los deseos y a la razón o inteligencia. Quizá sería oportuno, entonces, preguntarse en vista a qué está orientada la paideía, especialmente la que se refiere a los deseos y pasiones, pues esta también estará relacionada a la condición del akratếs.

Existen dos formas generales en las cuales esto puede verse: en relación a la ciudad y a la vida de cada ciudadano. Aristóteles menciona que los legisladores deben preocuparse por la educación especialmente de los jóvenes, ya que a partir de ella se germinan los hábitos y se moldea el carácter, los cuales influyen en la estabilidad y preservación del régimen político de la ciudad, y, asimismo, porque para el ejercicio de las facultades, artes y virtudes es necesario cultivar los hábitos adecuados (Aristóteles 1988a, 1137a19-22). Con todo, en cuanto al segundo punto, debe recordarse que algunas ocupaciones son necesarias en la ciudad y, en esa línea, también lo es estar en un periodo de guerra en un determinado momento, pero tanto una como otra cosa son en vista de algo superior y más digno: el ocio (Aristóteles 1988a, 1338a) y la paz. Mientras mayor sea el ocio para un ser, mayor será su capacidad de disfrutar, ser autosuficiente, vivir en un estado placentero y ejercer una actividad cuyo fin sea intrínseco a ella (Aristóteles 1985a, 1177b16-24). Si esto es así, “(...) es manifiesto que también deben aprenderse y formar parte de la educación ciertas cosas con vistas a un ocio en la diversión, y que esos conocimientos y disciplinas tengan en sí mismos su finalidad, mientras que los que se refieren al trabajo deben considerarse como necesarios y con vistas a otras cosas" (Aristóteles 1988a, 1338a9-13). ¿Qué actividades, entonces, son adecuadas para ejercerse en el ocio? La gramática, el dibujo, la cultura física y la música (mousikế). Esta última, siguiendo a Lord (1982, 66, 86-87), en su sentido más inclusivo distingue, mas no excluye, en sí a la música y a la poesía, ambas son útiles para la educación en la virtud moral. Para evaluar en qué medida esta última 
afirmación puede ser plausible para el hombre acrático, a continuación, me enfocaré en la tragedia, en específico, como uno de los tipos de poesía ${ }^{21}$.

Según la Poética, la tragedia es "(...) imitación (mímēsis) de una acción esforzada y completa, de cierta amplitud, en lenguaje sazonado, separada cada una de las especies [de aderezos] en las distintas partes, actuando los personajes y no mediante relato, y que mediante compasión y temor lleva a cabo la purgación (kathársis) de tales afecciones (páthēmatos)"22 (Aristóteles 1999, 1449b24-28). Esta definición ha sido muy estudiada y debatida por diversos especialistas ${ }^{23}$, por lo que aquí mi interés es llamar la atención sobre algunos puntos que guiarán la argumentación posterior. Un primer punto a comentar es la relación entre ética, política y poesía. A diferencia de Platón, Aristóteles no creía que la poesía debía estar subsumida y limitada a fines del Estado, como puede verse, por ejemplo, en un pasaje del capítulo 25 de la Poética, en el que Aristóteles defiende a los poetas en contra de aquellos que desmerecen el arte por decir cosas que no son verdaderas, i.e., sobre los dioses: los poetas pueden representar a dioses y hombres como deben ser, incluso según como les parezca. El poeta tiene derecho a alejarse de los hechos y construirlos según lo que la gente diga o él crea (Aristóteles 1999, 1460b32-35). Sin embargo, dos cosas: respecto a su relación con la ética, como será mostrado en lo siguiente, por lo pronto se puede decir que, aunque la poesía no está subyugada a esta, ya desde su construcción interna guarda una estrecha relación por la acción e imitación. Por otro lado, para Aristóteles la poética tiene su propia coherencia interna. En el teatro, el poeta es el arquitecto; pero esto no significa que no pueda tener, en ciertos contextos, un uso político, como en la educación de los ciudadanos ${ }^{24}$.

21 Para un estudio detallado e interesante sobre la relación entre la música, el ocio, la educación y la política en Aristóteles, véase Lord (1982).

22 Asimismo, el efecto de la tragedia es resultado de seis componentes: la fábula (mýthos), el carácter (êthos), el pensamiento (diánoia), la dicción (léxis), la música (melopóia) y el espectáculo (ópsis) (Aristóteles 1999, 1450a8-14).

23 Véase, por ejemplo, a Leighton (1982), Lord (1982), Daniels y Scully (1992), Fortenbaugh (2006) y Ford (2015).

24 Tal como puede verse en el libro VII de la Política, especialmente, 1341a18 y 1341b181342b35. Cf. Lord 1982, 151-153; Ford 2015, 13. 
Un segundo punto a comentar es la noción de mímēsis. La poesía surge de las inclinaciones humanas hacia la imitación y de la connaturalidad en el hombre del ritmo y la melodía (Aristóteles 1999, 1448b4-19). De estas, la primera tiene una causa intelectual: el hombre adquiere por imitación sus primeros conocimientos. Pero estos conocimientos no están reservados para los filósofos -o los poetas- exclusivamente, sino que son para todos (Aristóteles 1999, 1448b14-15). Por otra parte, es interesante señalar que el tipo de hombre y acciones más aptos para imitar en la tragedia son las de aquel que se halla entre los dos extremos de la virtud y el vicio, pues solo ellos pueden inspirar temor y compasión en los espectadores a partir de la estructura de la trama. Este personaje intermedio no sobresale por su virtud y justicia, ni tampoco cae en la desdicha por su bajeza y maldad, sino por algún tipo de yerro (hamartía) (Aristóteles 1999, 1453b). Para ahondar en la pregunta por la naturaleza de la catarsis $y$, de paso, centrar ya lo anterior, quisiera revisar las pasiones a ella -y la tragedia, en específico- ligadas.

Abordaré de manera breve dos de las pasiones en juego que no llegué a explorar en la segunda sección: el temor (phóbos) y la compasión (éleos). Para ello, acudiré a nueva cuenta a la Retórica. Allí, Aristóteles define al temor como "(...) un cierto pesar o turbación, nacidos de la imagen de que es inminente un mal destructivo o penoso" (1990, 1382a23-24). Es una especie de expectación de un mal (Aristóteles 1985a, 1115a10). "[E]s forzoso que tengan miedo quienes creen que van a sufrir algún mal" (Aristóteles 1990, 1382b39-1383a; cursiva mía). El pensamiento o creencia en un peligro inminente (sea este aparente o real) es esencial al miedo. El aspecto cognitivo está ligado a la conceptualización de las emociones. Ahora bien, esto es solo una ejemplificación de lo expuesto en §2; no obstante, ¿es relevante este aspecto para esta propuesta de la tragedia como una herramienta para el hombre acrático? En definitiva, y considero que líneas más adelante se puede ver por qué. Aristóteles señala que "<para sentir miedo> es, más bien, preciso que aún se tenga alguna esperanza de salvación por la que luchar. Y un signo de ello es que el temor hace que deliberemos (phóbos bouleutikoùs poieî), mientras que nadie delibera sobre cosas desesperadas" (1990, 1383a8-9). Lo que me interesa resaltar de este pasaje de la Retórica es que no solo está presente la relación entre la cognición y las pasiones, sino que la experiencia de ciertas pasiones, como el temor, puede servir 
como causa eficiente y apoyo a la deliberación y, por ende, a la elección. Esto confirma que las pasiones no son inherentemente negativas ni deben intentar eliminarse: necesitan ser educadas y canalizadas de forma correcta o virtuosa por la recta razón. Ello es significativo para la experiencia del hombre acrático, pues la buena tragedia suscita temor.

¿Y la compasión? La compasión es un “(...) cierto pesar por la aparición de un mal destructivo y penoso en quien no lo merece, que también cabría esperar que lo padeciera uno mismo o alguno de nuestros allegados, y ello además cuando se muestra próximo" (Aristóteles 1990, 1385b14-17). El temor y la compasión están conectados -uno puede llevar al otro-, pues “(...) son (...) temibles todas las cosas que, cuando les suceden o están a punto de sucederles a otros, inspiran compasión" (Aristóteles 1990, 1382b25). Esto es importante porque sugiere cómo podría actuar la catarsis: el hombre experimenta miedo a través de la compasión que siente hacia quien ha caído en desgracia en la tragedia. Pero esto solo puede suceder porque el hombre cree que también podría sucederle a él ${ }^{25}$.

Como no puede asegurarse una vida virtuosa para los hombres solamente por la coerción de la ley, su propia naturaleza o el uso de su razón -fue vista ya, en efecto, la figura del hombre acrático-, se mencionó que la educación en hábitos estaba dirigida principalmente a la parte deseosa (orektikòn/epithymētikòn) o pasional (pathētikòn) del alma; asimismo, a la definición de tragedia señalada pertenece la facultad de poder generar una purgación de afecciones a través de la compasión y el temor. Tras lo visto hasta el momento, uno puede preguntarse si esta purgación o catarsis es exclusiva de las pasiones de miedo y compasión o si puede extenderse a otras pasiones del alma, con lo cual se trasluciría la importancia de su función pedagógica en los hombres. Un pasaje que sugiere que sí se halla en la Política. Tras señalar que se ocupará de la naturaleza de la catarsis en la Poética, Aristóteles arguye que la mousikế debe cultivarse con vistas a la educación y la purificación:

25 El hombre se compadece con quien es semejante a él en edad, costumbres, modo de ser, categoría o linaje. Véase Aristóteles 1990, 1386a25-30; 1999, 1453a ss. 
Pues la emoción que se presenta en algunas almas con mucha fuerza se da en todas, pero en una en menor grado y en otra en mayor grado, como la compasión, el temor y también el entusiasmo. Algunos incluso están dominados por esta forma de agitación, y cuando se usan las melodías que arrebatan el alma vemos que están afectados por los cantos religiosos como si encontraran en ellos curación y purificación. Esto mismo tienen forzosamente que experimentarlo los compasivos, los atemorizados $\mathrm{y}$, en general, los poseídos por cualquier pasión, y los demás en la medida en que cada uno es afectado por tales sentimientos, y en todos se producirá cierta purificación y alivio acompañado de placer. (1988a, 1342a7-17, cursiva mía)

En el fragmento considerado la catarsis se extiende a "cualquier pasión", pero si lo hace suscitando compasión y temor, estas pasiones pueden tener un tinte específico. Encuentro interesante el que Lord (1982, 161163) ligue estas afecciones al thymós ("corazón" o spiritidness) del alma. ¿Es justificada esta posición? Justamente, al discutir sobre el carácter particular de los ciudadanos en la ciudad ideal, Aristóteles señalaba que, "(...) para dejarse conducir dócilmente por el legislador hacia la virtud, los hombres tienen que ser de natural inteligente y animoso (dianoētikoús te eînai kaì thymoeideîs)" (1988a, 1327b36-38). Asimismo, el thymós que debe caracterizar a los guardianes tiene una doble naturaleza: puede ser amable (con los conocidos y amigos) como fiero e irritable (con los desconocidos) (Aristóteles 1988a, 1327b5-1328a) ${ }^{26}$. En ese sentido, el thymós en algunas de sus manifestaciones es una pasión noble (pues a partir de ella el hombre puede proteger a sus amigos), pero también por ella se es capaz de experimentar otro tipo de pasiones, tales como ira, venganza, celos, etc., pasiones que, especialmente en el caso de la primera, han recibido un gran tratamiento en la Ética Nicomáquea VII por ser aquellas que justamente experimenta el hombre acrático (Aristóteles 1985a, 1149a25). En efecto, “(...) la ira (thymós) oye, pero, a causa del acaloramiento y de su naturaleza precipitada, no escucha lo que se le ordena y se lanza a la venganza. La razón, en efecto, o la imaginación le indican que se le hace un ultraje o un desprecio, y ella, como concluyendo que debe luchar contra esto, al punto se irrita" (Aristóteles

26 Aristóteles señala que esta es una "afirmación de algunos", pero en lo que sigue no la rechaza y, tras su caracterización y comentario, da el asunto por concluido "aproximadamente", pues "no debe buscarse la misma exactitud en las discusiones teóricas que en lo que es dado en los sentidos" (1988a, 1328a17-23). 
1985a, 1149a28-1149b1). Para Aristóteles, el thymós es menos vergonzoso que los apetitos o deseos porque al menos escucha al lógos. Siguiendo con el argumento anterior, si el thymós está relacionado con la defensa de los "nuestros" frente a "otros" y con aquello que en cierta medida mantiene los lazos internos entre los hombres, no es descabellado pensar que esta pasión tiene una importancia para la ciudad mejor o ideal, así como que une a los hombres y la vida política. Por el mismo motivo necesita un tipo de canalización adecuada, pues una mala disposición y uso de ella puede dificultar o imposibilitar la consecución del buen vivir para los ciudadanos.

Efectivamente, como señalaba Aristóteles en la Ética Nicomáquea, el punto no es que el hombre deba suprimir sus pasiones o evitarlas; por el contrario, experimentar una pasión de la forma en que se debe y en el momento adecuado puede ser muy útil (1985a, 1109b15) cuando está dirigida a un fin mayor a ella misma -mejor aún si esto es dictado por el lógos. Ahora bien, ¿tiene sentido pensar estas afecciones o pasiones en el caso de la tragedia griega? A mi parecer sí, pues en las obras que cita Aristóteles en la Poética como ejemplos de buenas tragedias, como Edipo en particular, las pasiones asociadas con el thymós -tales como el miedo, la compasión, la indignación, la cólera, los celos, etc.- son materia bastante común y tienen utilidad en la estructura de la obra. Bajo esta perspectiva, tiene sentido pensar que "(...) cathartic tragedy would thus serve as the education par excellence of spirited gentlemen in the political virtue or prudence" (Lord 1982, 164). Este, a mi parecer, es argumento importante para considerar a la función catárquica de la tragedia como útil para la educación de las personas en general y también del akratếs. No obstante, considero que existen unos aspectos más que también deben ser considerados respecto a la estructura misma de la tragedia y la función de la cognición realizada en ella.

Un punto crucial -que, desde luego, se aplica también a la tragedia- señalado por Aristóteles sobre la poesía es que esta, a diferencia de la historia, "es más filosófica y elevada", pues dice lo general, mientras que esta última se ocupa de lo particular (1999, 1451b5-6). La poesía es más general porque se refiere a los tipos de hombres que hacen o dicen cosas de forma verosímil o necesaria, mientras que la historia se ocupa de lo que hizo una persona determinada. Al imaginarse la poesía lo que hace o dice un 
personaje histórico o creado, construye tipos o modelos de carácter. Pero no son cualquier clase de modelos sino, particularmente, modelos éticos. En palabras de Else: "What it [poetry] can offer us is a view of the typology of human nature, freed from the accidents that encumber our vision in real life. It can show us 'what kind of thing such and such a kind of man will naturally say or do' under given circumstances" $(1957,305)$. Es interesante que estos modelos no sean ni perfectos (virtuosos) ni imperfectos (malos), sino "intermedios", no sobresalen ni por virtud ni por maldad, y que caen en desdicha por algún yerro (Aristóteles 1999, 1453a7-10)27. Esto permite una identificación mucho más efectiva para la mayoría de los hombres -no perfectos, pero tampoco viciosos- $y$, más aún, que un hombre piense que lo que les sucede a estos personajes también podría ser reflejado en ellos -especialmente para quienes son incontinentes. Ello sucede, pues, a través de la noción de error (hamartía).

Tal como las acciones son complejas, las fábulas -centrales en la estructurade las tragedias lo son también (Aristóteles 1999, 1452a12-17). Aristóteles concibe "compleja" una tragedia en la que hay un cambio de fortuna con peripecia (peripéteia), agnición (anagnórisis) o ambas. La peripecia es el cambio de la acción en sentido contrario, de forma verosímil o necesaria ${ }^{28}$.

27 Aristóteles señala que los personajes trágicos deben ser "intermedios" porque, en términos generales, son ellos quienes pueden inspirar efectivamente compasión y temor en el público a través de la identificación y semejanza -tal como fue, asimismo, visto en el breve estudio de las pasiones hecho en \$2-. Ahora bien, ¿quién es ese público? Aristóteles habla de un "nosotros" $(1999,1453 a 5)$, pero ¿cómo "estamos" representados?, ¿ese "nosotros" puede incluir al akratếs? Aunque es difícil saber con exactitud en quiénes pensaba Aristóteles, considero que hay algunas pistas que pueden apoyar una respuesta positiva a esta pregunta. ¿Qué caracteriza a estos personajes intermedios? No son virtuosos ni viciosos. Tampoco son, desde luego, "hombres divinos" ni son intemperantes o brutales -estas clasificaciones pertenecen a los extremos descritos en la Ética Nicomáquea VII (Aristóteles 1985a, 1145a) y no son comunes. ¿Qué queda en ese "intermedio"? De la manera en que yo lo entiendo, hombres continentes, hombres incontinentes -no siempre de manera "absoluta", ciertamente, sino también de manera "parcial", respecto a algo, por ejemplo, la riqueza, los honores, etc., y no necesariamente siempre. Más aún, otro aspecto que me parece que apoya esta interpretación se verá a continuación con la relación entre la hamartía y los dos tipos de akrasía discutidos anteriormente en $\S 2$.

28 Tal como señala, por ejemplo, García Yebra, "En el Edipo Rey, vv. 924 ss., llega de Corinto un mensajero con la noticia de que ha muerto Pólibo, rey de aquella ciudad, cuyo trono corresponde a Edipo. Pero este se muestra temeroso de cometer incesto con Mérope, viuda de Pólibo, a la que él considera su madre. El mensajero cree librarle de este temor revelándole que Pólibo y Mérope no eran sus padres. Pero este descubrimiento produce en Edipo el efecto 
La anagnórisis, por su parte, es un "(...) cambio desde la ignorancia al conocimiento (ek agnoías eis gnôsin metabolế), para amistad o para odio, de los destinados a la dicha o al infortunio. Y la agnición más perfecta es la acompañada de peripecia, como la de Edipo" (Aristóteles 1999, 1452a2933). La imitación de la anagnórisis en la vida de los hombres sería, en efecto, lo que podría ayudar a encauzar las pasiones del hombre acrático en quien, como fue visto, se salva lo "mejor", o sea, el principio. La manera en que esto ha de darse puede estar ligada a la hamartía ${ }^{29}$, pues esta sirve como ese vínculo causal que permite que el protagonista pase de un estado de ignorancia a reconocimiento.

La hamartía es considerada como un término que posee un amplio bagaje de significados: a grandes rasgos, como un error moral, un error o ignorancia de hechos, un error de identidad (Stinton 1975; Schutrumpf 1989; Kim 2010). "The senses of ámapría can be grouped under three main headings: to miss the mark (literally); to fail in some object or make a mistake; and to offend morally, to do wrong" (Stinton 1975, 222). Me detendré en este punto en función a los tipos de akrasía expuestos en \$2. Por un lado, se mencionó que el akratếs no puede aplicar, en el segundo silogismo, la regla general a la cosa particular debido a la ignorancia de esta premisa. Este caso es el más afín a la caracterización de la hamartía como un error o ignorancia de hechos e identidad, tal como está expuesto en Else (1957, 383) y Cyzyk (1990, 25). El caso de Edipo es emblemático en esta categoría. En este sentido, en efecto, la identificación entre el akratếs y el personaje trágico es mayor. Por otro lado, está el otro caso, el del akratếs que no puede llevar a la acción el silogismo práctico debido a la intervención de sus pasiones. ¿Sería de utilidad la exposición ante la hamartía trágica también para este akratếs? Brevemente, siguiendo lo expuesto por Stinton (1975), lo sería, dada la dimensión de error "moral" (moral flaw) de la hamartía. En la Ética Nicomáquea, Aristóteles dice lo siguiente: “(...) la incontinencia

contrario: le abre los ojos a la tremenda realidad de que ha matado a su verdadero padre, Layo, y se ha casado con Yocasta, su verdadera madre" (Aristóteles 1999, 279).

29 El intrincado debate sobre la naturaleza de la hamartía no puede ser tocado en estas páginas. Algunos de los autores revisados que incluyen en sus trabajos discusiones al respecto son Else (1957, 378-385), Stinton (1975), Lord (1982, 165-174), Schutrumpf (1989) y Kim (2010). El trabajo de Stinton (1975) me ha sido especialmente útil. 
se censura no solo como una falta (hamartía), sino como un vicio (kakía)" (1985a, 1148a2-4). Como el vicioso, el incontinente puede realizar actos injustos; pero, a diferencia de él, no lo hace por una elección deliberada, sino en contra de esta y de su razón (Aristóteles 1985a, 1148a9-11). Los actos injustos que se realizan sin deliberación a través de un impulso humano o alguna pasión ${ }^{30}$ son adikémata (Aristóteles 1985a, 1135b22-25) y son, también, hamartía. Asimismo, califican también como hamartía aquellos actos acráticos, como veíamos en $\$ 2$, relacionados con las actividades de naturaleza intermedia, tales como la adquisición de bienes materiales, el honor, la riqueza, etc. (Stinton 1975, 232) ${ }^{31}$.

A partir de estos elementos y del trasfondo de la discusión de la tragedia, es posible repensar la acción que lleva a cabo el hombre acrático. Como fue señalado en la primera parte de este trabajo, el hombre acrático falla al llegar a la conclusión del silogismo práctico y al tener y no tener, "en cierto modo", el entendimiento; falla porque se ve arrastrado por el deseo, producto de un conflicto entre este y su lógos. En el acto trágico, el hombre acrático no solo ve el error representado, sino que lo experimenta como un punto importante de la estructura causal de los hechos que el héroe trágico experimenta y actúa. Se debe tener en cuenta que, como Lord señala, en la

30 Una ejemplificación de ello, tal como fue visto en §2, se halla en la Ética Eudemia: "Pero, además, la corrupción y perversión de cada ser no <se mueve> al azar en una dirección cualquiera, sino en dirección a los estados contrarios o intermedios. En efecto, no es posible salirse de éstos, puesto que incluso el error no lleva a una cosa cualquiera al azar, sino a los contrarios donde hay contrarios y a aquellos contrarios que lo son según la ciencia. Es, pues, necesario que el error y la elección vayan del término medio hacia los contrarios (los contrarios del término medio son el exceso y el defecto)" (Aristóteles 1985b, 1227a31-38). Las primeras líneas son un poco desconcertantes. Según lo que hemos visto, ¿cómo puede la hamartía tender hacia un estado intermedio? Concuerdo con Simpson (2013, 279-280) en que la manera en que ello podría pensarse de ese modo es si es que por influencia del placer y el dolor-aquellas que Aristóteles identifica como "causas" líneas más adelante- uno experimentase un vicio como si fuese un estado intermedio -en el que usualmente entendemos la virtud-, esto es, de manera engañosa. Lo que reafirmaría esta interpretación es que, efectivamente, Aristóteles señala que “(...) las causas son el placer y el dolor, porque las cosas están hechas de tal manera que lo agradable parece bueno al alma, y lo más agradable mejor, mientras lo más penoso parece malo, y lo más penoso, peor" (Aristóteles 1985b, 1227a38-41; cursiva mía).

31 "But ảkpaбía in respect of honour, etc., though a weakness, is not called a vice because honour is in itself a good. Such weaknesses, which are culpable but not very, are especially suitable for the undeserved misfortune of tragedy, and it is no accident that Aristotle cites

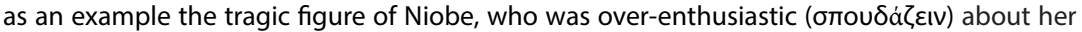
children-such enthusiasm being in itself a good, but not in excess (1148a31-4)" (Stinton 1975, 232). 
visión de tragedia que Aristóteles sostiene se insiste en la responsabilidad moral de los héroes: "Aristotle's own theory (...) would appear to require that the hero's downfall follow unambiguously from his moral error, or that the hero be held unambiguously responsible for yielding to the passion which occasions the tragic deed" $(1982,172)$. Este aspecto permite que, ya que el hombre acrático ve representado el estado de conflicto entre su lógos y sus pasiones en la acción trágica, de alguna manera, se vea asimismo interpelado sobre el nivel de responsabilidad que conllevan sus acciones.

La importancia de esto, me parece, se fundamenta principalmente de la siguiente manera: el que el akratếs pueda ver la secuencia causal, necesaria y/o verosímil -en la que tanto insiste Aristóteles como condiciones para una buena tragedia- no solo lo conecta con el ámbito racional de la tragedia, sino también con su dimensión kalós (bello, adecuado). No me es posible entrar en un estudio mayor al respecto, pero sí podría quizá traerse a colación lo que Aristóteles expresa en Metafísica M: las formas supremas o especies principales (mégista eídē) de la belleza o fineness (kalós) son el orden (táxis), la proporción (symmetría) y la delimitación (ōrisménos) (1994b, 1078a35-38). En el mundo sensible, siguiendo lo expuesto en Metafísica $\Lambda$, el orden es la disposición de las partes de un todo con referencia a un fin en común, o sea, como una disposición teleológica (Aristóteles 1994b, 1075a11-16). En ese sentido, según Richardson (2004, 127-129), la simetría y la delimitación se entienden en el mismo sentido, pues algo muestra simetría o proporción cuando el tamaño de sus partes conduce a su bien o fin. En el segundo caso, el que las cosas tengan una delimitación o límite les permite estar de la forma adecuada para poder cumplir su función. Pero estas son también características que Aristóteles señala deben estar presentes en la buena poesía. En efecto, Aristóteles apunta que, por ejemplo, la fábula debe ser del tamaño apropiado porque, en caso contrario, no sería comprendida y se perdería en la gente que la contempla, pero si es muy breve, tampoco la gente podrá verla en lo absoluto (Aristóteles 1999, 1450b36-1451a6; un apunte similar en Aristóteles 1985a, 1123b7).

Por otra parte, lo que parece sugerir justamente la importancia de la dimensión kalós -ya sea en la virtud, en las artes, entre otros- es que la orientación teleológica de algún elemento que posee esta dimensión involucra ya, en 
cierto grado, una visibilidad ante otros. Este aspecto es llevado a cabo de manera magistral en el arte poético, a diferencia de la música y retórica. En esa línea, se podría conectar esta visibilidad con el tipo de placer que se experimenta al apreciar el arte poético -por ejemplo, una tragedia- y el proceso cognitivo que se lleva a cabo enlazado a él. Como fue visto, una de las formas en que la poesía conecta con las pasiones del espectador es a través de la identificación entre el contenido que ofrece y lo propio que vive y experimenta aquel. Sin embargo, la fábula, se puede pensar, no es una réplica de la vida del hombre particular-por ejemplo, el akratếs-que está expuesto a ella. Por el contrario, tiene elementos propios y particulares, ya sea en la música, espectáculo, diálogo o en la misma narración, que fuerzan al espectador a realizar un esfuerzo para encontrar un sentido en ella, para comprenderla e interpretarla. No es un proceso pasivo -aun si esto particularmente no es relevante para la misma construcción de la poesía-, sino reactivo en la particularidad de cada persona que contempla. Aunque el proceso cognitivo no es, evidentemente, el mismo que se lleva a cabo en la actividad teorética, este, en particular, tiene sus propias ventajas. Una de ellas es el ser accesible a todos (y esto es importante en el caso del hombre acrático porque el bloqueo de ciertas capacidades cognitivas suyas es asimismo símbolo de que no está capacitado en virtudes y hábitos más dignos), a diferencia de la otra actividad.

Finalmente, hay un último aspecto que apoya esta argumentación. Al hablar en la Poética del origen de la poesía, Aristóteles señala que, al contemplar las imágenes, el hombre aprende (manthánein) y deduce (syllogízesthai) qué es cada cosa (1999, 1448b15-20). De manera general, la poesía tiene dos ventajas: cumple los requisitos vistos para que algo sea kalós y al mismo tiempo es, sobre todo, visible. Porque es visible, el poeta es capaz de representar lo universal (y hasta abstracto) de maneras muy concretas en acciones morales determinadas. Pero, de manera más particular e importante para la tragedia, ambas tienen como característica que interpelan a quien las aprecia incluso hasta el punto de que busquen el "por qué". "¿Por qué tal determinado héroe cayó en desgracia? Porque...". La poesía, a pesar de no poseer una exigencia inferencial como la de las ciencias teoréticas, sí exige la comprensión de patrones de conducta causales para poder aprehender la fábula en cuestión, disfrutarla plenamente y poder realizar el acto 
catárquico. Con lo visto sobre las pasiones en §2, si la concepción de estas contiene un componente cognitivo, con mucha más razón una exposición a una obra trágica que produzca cierto tipo de pasiones, catarsis y reflexión puede ser de utilidad. Por todo lo anterior, se concluye que la tragedia puede brindar herramientas para que el "arrepentimiento" del hombre acrático se lleve a cabo porque tiene un factor intelectual (que cuestiona el "por qué", más que el "qué", como la historia) pero, sobre todo, porque apunta hacia -y trabaja desde- las pasiones de dicho individuo.

Recibido: $14 / 01 / 2020$

Aceptado: 08/03/2020

\section{Bibliografía}

Aristóteles, 1934. The Nicomachean Ethics. Traducción de Harris Rackham. Cambridge: Harvard University Press.

- 1944. Politics. Traducción de Harris Rackham. Cambridge: Harvard University Press.

- 1978. Acerca del Alma I. En: Acerca del Alma. Traducción de Tomás Calvo Martínez. Madrid: Gredos, 131-167.

- 1985a. Ética Nicomáquea. En: Ética Nicomáquea, Ética Eudemia. Traducción de Julio Pallí Bonet. Madrid: Gredos, 129-409.

- 1985b. Ética Eudemia. En: Ética Nicomáquea, Ética Eudemia. Traducción de Julio Pallí Bonet. Madrid: Gredos, 413-547.

- 1988a. Política. Traducción de Manuela García. Madrid: Gredos.

- 1988b. Analíticos Segundos. En: Tratados de Lógica (Órganon) II. Traducción de Miguel Candel. Madrid: Gredos, 313-440.

- 1990. Retórica. Traducción de Quintín Racionero. Madrid: Gredos.

- 1994a. Ética a Nicómaco. Traducción de María Araujo y Julián Marías. Madrid: Centro de Estudios Constitucionales.

- 1994b. Metafísica. Traducción de Tomás Calvo. Madrid: Gredos.

- 1999. Poética. Traducción de Valentín García. Madrid: Gredos.

Aufderheide, Joachim, 2016. Aristotle Against Delos: Pleasure in Nicomachean Ethics X. Phronesis, 61 (3), 284-306.

Bywater, Ingram, 1890. Aristotelis Ethica Nicomachea. Cambridge: Cambridge University Press. 
Charles, David, 2009. Nicomachean Ethics VII.3: Varieties of akrasia. En: Aristotle's Nicomachean Ethics, Book VII, ed. Carlo Natali. Oxford: Oxford University Press, 41-71.

Cope, Edward y John Sandys, 2009. Aristotle: Rhetoric. Volume 2. Cambridge: Cambridge University Press.

Czyzyk, Mark, 1990. Hamartia, Akrasia, Ignorance and Blame in Aristotle's Philosophy. Kinesis 20 (1), 17-35.

Daniels, Charles y Sam Scully, 1992. Pity, Fear, and Catharsis in Aristotle's Poetics. Noûs 26 (2), 204-222.

Else, Gerald, 1957. Aristotle's Poetics: The Argument. Cambridge: Harvard University Press.

Ford, Andrew, 2015. The Purpose of Aristotle's Poetics. Classical Philology 110, 1-21.

Fortenbaugh, William, 2006. Aristotle's Rhetoric on Emotions. En: Aristotle's Practical Side: On his Psychology, Ethics, Politics and Rhetorics. Boston: Brill, 9-39.

Harte, Verity, 2014. The Nicomachean Ethics on Pleasure. En: The Cambridge Companion to Aristotle's Nicomachean Ethics, ed. Ronald Polansky. Cambridge: Cambridge University Press, 288-319.

Heath, M.F., 2009. Cognition in Aristotle's “Poetics". Mnemosyne 62, 51-75.

Henry, Devin, 2002. Aristotle on Pleasure and the Worst Form of Akrasia. Ethical Theory and Moral Practice 5, 255-270.

Kim, Ho, 2010. Aristotle's "Hamartia" Reconsidered. Harvard Studies in Classical Philology 105, 33-52.

Leighton, Stephen, 1982. Aristotle and the Emotions. Phronesis 27 (2), 144-174.

Lorenz, Hendrik, 2014. Aristotle's Analysis of Akratic Action. En: The Cambridge Companion to Aristotle's Nicomachean Ethics, ed. Ronald Polansky. Cambridge: Cambridge University Press, 242-262.

Lord, Carnes, 1982. Education and Culture in the Political Thought of Aristotle. Londres: Cornell University Press.

Nussbaum, Martha, 1978. Practical Syllogisms and Practical Science. En: Aristotle's De Motu Animalium, Princeton: Princeton University Press, 165-220.

- 1990. La vulnerabilidad de la vida buena del ser humano: los bienes relacionales. En: La fragilidad del bien: Fortuna y ética en la tragedia y filosofía griega. Madrid: Visor, 431-463.

Oriol, Manuel, 2004. La estructura del silogismo práctico en Aristóteles. Revista de Filosofía, 29 (1), 53-75.

Richardson, Gabriel, 2004. Moral Virtue and To Kalon. En: Happy Lives and the Highest Good: An Essay on Aristotle's Nicomachean Ethics. Princeton: Princeton University, 123-147. 
Rorty, Amélie, 1980. Akrasia and Pleasure. Nicomachean Ethics Book 7. Essays on Aristotle's Ethics. California: University of California Press, 267-285.

Simpson, Peter, 2013. Commentary on the Eudemian Ethics. En: The Eudemian Ethics of Aristotle. Traducción de Peter Simpson. New Jersey: Transaction Publishers, 195-393.

Tracy, H.L., 1946. Aristotle on Aesthetic Pleasure. Classical Philology 41, 43-46.

Schutrumpf, Eckart, 1989. Traditional Elements in the Concept of Hamartia in Aristotle's Poetics. Harvard Studies in Classical Philology 92 (137), 137-156.

Stinton, T., 1975. Hamartia in Aristotle and Greek Tragedy. The Classical Quarterly 25 (2), 221-254. 